\title{
DINÂMICA DE PODER NOS ESPAÇOS ORGANIZACIONAIS DE UMA ADMINISTRADORA DE SHOPPINGS CENTERS: UM ESTUDO ETNOGRÁFICO
}

\author{
POWER DYNAMICS INSIDE THE ORGANIZATIONAL SPACES OF A MALL MANAGEMENT \\ COMPANY: AN ETHNOGRAPHIC STUDY
}

\section{Luiz Abiel Rabelo Martins}

abiel.luiz@gmail.com

Pontifícia Universidade Católica do Rio de Janeiro, Rio de Janeiro/RJ, BRASIL

\section{Andrea Cherman}

acherman@iag.puc-rio.br

Pontifícia Universidade Católica do Rio de Janeiro, Rio de Janeiro/RJ, BRASIL

\section{Resumo}

O estudo do poder nas organizações é um dos meandros para a compreensão de uma empresa e seus vieses de gerenciamento, revelando mecanismos de dominação na modernidade. O presente trabalho, de caráter etnográfico, objetivou analisar e descrever criticamente como a obrigatoriedade da exposição do espaço físico de trabalho interfere no comportamento do indivíduo e na dinâmica de poder, tendo como base as ideias de Foucault (2002). Foram observadas as interações entre os indivíduos no local de trabalho e a exposição proporcionada pela distribuição dos corpos em diferentes ambientes organizacionais. Os achados revelam quatro espaços emergentes - coercitivo, conflituoso, passivo e catártico -, com distintas dinâmicas de poder, que impactam no comportamento dos indivíduos.

Palavras-chave: Poder nas organizações. Foucault. Espaços organizacionais. Etnografia.

\section{Abstract}

The study of power in organizations is one way to understand a company and its management philosophy, revealing modern mechanisms of domination and hierarchy. This ethnographic study, based on Foucault's work (2002), analyzes how power-related tactics are revealed in organizational spaces. Interactions between individuals in the workplace are observed across their distribution in various corporate divisions. The observations revealed four emerging mechanisms of domination in the workplace - coercive, conflicted, passive and cathartic - each of which have their own power dynamics that influence the behavioral outcomes of individuals in organizational environments.

Keywords: Power in organizations. Foucault. Organizational spaces. Ethnography. 


\section{Introdução}

Os ambientes organizacionais, em geral, podem ser entendidos como objeto de práticas e intervenções sociais diversas. Por isso, elementos como o espaço físico de trabalho tendem a influenciar diretamente na maneira como os indivíduos vão interagir e produzir (VERGARA, 2006). Para Barley, Brain e Taylor (apud ALCADIPANI; ALMEIDA, 2000), o local de trabalho classicamente as fábricas, escritórios e hospitais - passou a ser considerado pelas ciências sociais como elemento independente da dinâmica e do processo de trabalho, sendo visto também como estrutura de controle.

É destacável que a compreensão do ambiente de trabalho não assume necessariamente papel neutro, pois, desde a sua origem, está ligado aos modelos de produção e aniquilamento da autonomia do trabalhador (ALCADIPANI; ALMEIDA, 2000). Um movimento importante para ilustrar tal questão é a mudança do design e layout, nos últimos anos, para o modelo de escritórios abertos. Os open offices, surgidos na Alemanha, em 1950, são caracterizados pela eliminação de portas, paredes e separações, demarcando um estilo de escritório com a finalidade de suprir, em um primeiro momento, a necessidade de comunicação entre os empregados (VERGARA, 2003).

Foucault (2002), nesse aspecto, converge para uma proposta radical crítica aplicável às organizações e ao indivíduo (FILHO, 2002). Destaca a análise do espaço organizacional como chave no processo de interação dos funcionários e, mais além, da identificação dos mecanismos de poder nas organizações. Portanto, o objetivo deste estudo é identificar e descrever criticamente como a obrigatoriedade da exposição do indivíduo no espaço físico de trabalho interfere no seu comportamento e na construção da dinâmica de poder, sob a ótica foucaultiana. Para ele, o exercício do poder é estabelecido de forma sutil, trazendo dinâmicas veladas de disciplinamento do próprio indivíduo (FOUCAULT, 2002; SEGNINI, 1986).

Para realização do estudo, foi feita uma pesquisa etnográfica, em uma empresa do ramo de shopping center. Como contribuição principal, o trabalho sugere análises sobre a dinâmica da prisão organizacional, com a qual sutilmente se depara o funcionário, e aprofunda-se em como as formas de comando e controle na contemporaneidade revelam os artifícios tênues do poder nas empresas. Como delimitação, o artigo se concentra, principalmente, nas discussões do espaço para Foucault (2002).
O texto está organizado em seis seções, incluindo esta introdução. A segunda seção discorre sobre o marco teórico utilizado; a terceira expõe os procedimentos metodológicos; a quarta apresenta a análise dos resultados; a quinta debate sobre o estudo; e a sexta encerra com a conclusão e sugestões para futuras pesquisas.

\section{Marco Teórico}

\section{O Poder para Foucault}

Não há, para Foucault (2002), uma teoria do poder, já que ele considera toda teoria provisória e passível de desvios. Por isso, segundo o autor, a composição do que é o poder faz parte de uma lógica cunhada nas relações entre os indivíduos, as quais assinalam condições sutis de controle na estrutura do poder $\mathrm{e}$ definem a concepção do que é a sociedade disciplinar. Para Foucault (2002, p. 141), a disciplina "individualiza os corpos por uma localização que não os implanta, mas os distribui e os faz circular numa rede de relações". Assim, essa "analítica do poder", para ele, alude aos artifícios de controle e manipulação latentes no âmbito dos estudos organizacionais. Foucault (2002) salienta que esses dispositivos do poder se configuram como métodos minuciosos das operações do corpo, que, assegurando a sujeição constante do vigiado, impõem-lhe a docilidade da dominação. Toda a dinâmica do poder, para Foucault (2002), define as bases do então poder disciplinar. $\mathrm{O}$ autor explica que, dentre os vértices fundamentais para compreensão do tema, está justamente a organização do espaço.

A gestão física do ambiente corporativo, conforme Foucault (2002), insere colaboradores em espaços já previamente determinados, submetendo-os, desse modo, a um controle tendencioso das atividades laborais, que culmina no objetivo maior de máxima produtividade para a empresa. $\mathrm{O}$ autor considera que: "Lugares determinados se definem para satisfazer não só à necessidade de vigiar [...] mas também de criar um espaço útil." (FOUCAULT, 2002, p. 139). É crítico ressaltar que Foucault (2002) delineia seus pensamentos com base no sistema penal europeu do fim do século XVIII. Por isso, suas ideias acerca do espaço adquirem caráter questionador sobre a privação da liberdade e a adequação da racionalidade humana. Para ilustrar tal preposição, o pensador explica o Panóptico de Bentham. 
Idealizada por Jeremy Bentham, no século XVIII, a figura do panóptico buscava modelar um sistema de prisão eficiente, no qual o detento não praticasse a desobediência ordenada. O ambiente do panóptico sugere espaços abertos, nus e totalmente visíveis, onde a fonte vigiadora está longe do alcance do olhar do vigiado; nele, todos são obrigatoriamente expostos, explanando na esfera uma constante sensação de monitoramento (FOUCAULT, 2002). O autor ressalta que a vigilância provocada pelo espaço garante a manutenção da ordem do ambiente pelos próprios indivíduos, o que é explicado não pela ordenação de uma figura central de poder, mas pela articulação de cada detento vigiado, que, por não saber se está ou não sendo monitorado, tende a moldar seu comportamento (MACHADO, 2002).

O envolvimento do indivíduo que culmina no seu próprio aprisionamento psicológico é conceitochave na obra de Foucault (2002). O relacionamento patológico do indivíduo na eficiência da manipulação se caracteriza nas empresas por estruturas espaciais de fomento ao controle invisível condicionado a todos na cadeia de relações do poder. Por isso, os mesmos indivíduos que exercem o poder são passíveis de experimentar suas ações, já que o espaço aberto expõe todos diante da camada organizacional e permite a deflagração em qualquer tempo, conforme discorre o próprio autor: "Importa estabelecer as presenças e as ausências [...]. Procedimento, portanto, para conhecer, dominar e utilizar. A disciplina organiza um espaço analítico." (FOUCAULT, 2002, p. 138).

\section{Dinâmica de Poder e Organização do Espaço}

Nos tempos modernos, a estrutura dos open offices remete ao conceito do panóptico. Acerca do assunto, Segnini (1986) investiga, também com base nos poderes disciplinares de Foucault (2002), as variáveis que compõem a estrutura do poder em um banco brasileiro, analisando, dentre os aspectos, a organização do espaço como fator relevante. A autora aponta que os fenômenos vivenciados no espaço aberto de trabalho evidenciam o envolvimento do indivíduo no seu monitoramento próprio e alheio, promovendo a manutenção do pensamento organizacional através da ordem e disciplina implícitas no espaço.

$\mathrm{Na}$ questão, Alcadipani e Almeida (2000) discutem o encantamento de funcionários diante da implementação de um escritório aberto. Para eles, as impressões reveladas durante as atividades de trabalho e a interação entre os colaboradores no novo espaço geram um ambiente de controle e monitoramento impulsionado, sobretudo, pela visibilidade fria do espaço. Os autores promovem a identificação do espaço aberto como ator intrínseco nas vivências de poder e na construção das relações, ou seja, independente de posição hierárquica, todos estão sujeitos às dinâmicas do poder.

$\mathrm{Na}$ mesma perspectiva, as análises de Townley (apud VERGARA, 2003) salientam que os estudos de Foucault (1979; 2002) fornecem uma alternativa para se perceber como as organizações, na contemporaneidade, empregam práticas disciplinares para criar conhecimento e fomentar as relações de poder. Para a autora, os indivíduos são alocados em espaços conceituais, conferindo ordem e clareza no processo de trabalho. Dessa forma, coloca-se em voga a reflexão sobre empresas como espaços analíticos do comportamento organizacional.

\section{Procedimentos Metodológicos}

A pesquisa deste trabalho foi realizada através do método descritivo (GIL, 2008), de natureza qualitativa e de caráter etnográfico. A pesquisa etnográfica permite peculiaridades ao observar o fenômeno, pois é delineado, aqui, um olhar de perto e de dentro do ambiente; e não um olhar marcadamente de longe e de fora (MAGNANI, 2002). A imersão no cotidiano do campo analisado, ainda de acordo com Magnani (2002), assinala um diferencial de compreensão do próprio indivíduo, já que é possível observá-lo no seu próprio campo de atuação.

Sobre a companhia analisada, ela é de porte médio se comparada aos grandes players do ramo. Com mais de dez anos de experiência no mercado, a empresa visa atender todas as etapas relacionadas a um shopping center. Possui aproximadamente cem funcionários, distribuídos em quatro unidades de negócios: Desenvolvimento, Comercialização, Gestão e Tecnologia. O escritório central localizavase, durante o exercício de observação, literalmente em uma casa. $\mathrm{O}$ ambiente de trabalho com aspecto residencial e a convivência dos trabalhadores nos cômodos/departamentos da empresa proporcionaram dinâmicas de teor único, as quais o presente artigo buscou explorar.

Nesse sentido, para elaborar este estudo, foi concebido um diário de campo conforme preconiza o método. 
Ele foi construído ao longo de reuniões, encontros de equipe, almoços, entre outros da empresa em questão. É importante ressaltar que as anotações acerca do cotidiano da organização foram realizadas sem nenhum juízo de valor, comprometendo-se os autores a analisar a dinâmica em si dos ambientes organizacionais e não isoladamente os indivíduos.

O universo da pesquisa foi o departamento de Desenvolvimento de Projetos da sede da companhia, localizada no Rio de Janeiro. A escolha segue os critérios de conveniência, relevância e intencionalidade. A amostra dos sujeitos é composta por oito colaboradores conforme características expostas na Figura 1. Para sistematização, no diário de campo, foram denominados pares: analistas e estagiários; e pares-chefia: Diretor, Gerente, analistas e estagiários.

Figura 1. Sujeitos do estudo

\begin{tabular}{|c|c|c|c|c|c|}
\cline { 2 - 6 } \multicolumn{1}{c|}{} & Formação & Universidade & Idade & Sexo & Nacionalidade \\
\hline Diretor & Engenharia Elétrica & PUC-Rio & 36 anos & M & Brasil \\
\hline Gerente & História da América Latina & Brigham Young University & 36 anos & M & EUA \\
\hline Analista 1 & Administração de Empresas & PUC-Paraná & 27 anos & F & Brasil \\
\hline Analista 2 & Administração de Empresas & IBMEC & 28 anos & F & Brasil \\
\hline Analista 3 & Ciências Econômicas & FGV & 26 anos & M & Brasil \\
\hline Estagiário 1 & Administração de Empresas & PUC-Rio & 24 anos & M & Brasil \\
\hline Estagiário 2 & Ciências Econômicas & PUC-Rio & 23 anos & F & Brasil \\
\hline Estagiário 3 & Engenharia de Produção & UFF & 23 anos & M & Brasil \\
\hline
\end{tabular}

Fonte: Desenvolvido pelos autores

Conforme mencionado, a prática da etnografia permitiu vivenciar direto no campo as variáveis que permeiam o indivíduo quando inserido em diferentes espaços organizacionais. Buscou-se, com o diário, registrar a percepção dos sentimentos por meio dos diálogos, discursos, atitudes, entonação, olhares, gestos e o próprio comportamento dos indivíduos. Cabe ressaltar que os espaços não foram definidos a priori. A partir do diário de campo, emergiram os espaços que apresentavam dinâmicas de poder relevantes para o estudo, a saber: a sala de reunião, o open office, copa e almoço fora da empresa. Eles são apresentados na Figura 2. Os ambientes também foram fotografados, assim como os espaços individuais dos sujeitos observados (suas mesas/espaços nas bancadas). Na sequência, os dados coletados nos diários e fotos foram tratados pela análise de conteúdo e significado comparado pelos diversos espaços onde as dinâmicas de poder ocorriam.

Figura 2. Espaços de análise

\begin{tabular}{|c|c|c|c|c|c|}
\hline & & \multicolumn{4}{|c|}{ Espaços } \\
\hline & & Sala de Reunião & Open office & Copa & Almoço fora da empresa \\
\hline \multirow{2}{*}{ Interações } & Entre pares & $\checkmark$ & $\checkmark$ & $\checkmark$ & $\checkmark$ \\
\hline & Pares-chefia & $\checkmark$ & $\checkmark$ & & \\
\hline
\end{tabular}

Fonte: Desenvolvido pelos autores

O período de observação foi de quatro meses, com início em abril de 2012 e término em julho de 2012, resultando em 42 páginas de anotações no diário de campo. Contudo, para melhor entendimento da dinâmica de poder e do comportamento nos espaços em questão, levou-se em consideração, na análise dos resultados, também a presença de um dos autores na empresa, desde setembro de 2011. 
É cabível neste contexto a percepção da essência e o compromisso com o método etnográfico. Para Adorno e Castro (1994), colocar-se dentro do campo analisado, exige do pesquisador um exercício reflexivo e constante da relação sujeito/objeto, onde o mesmo se põe disponível para a revisão de conceitos e concepções, abrindo possibilidades de perspectivas que rondam os indivíduos do fenômeno. Por isso, todo detalhe da interação dos indivíduos foi anotado como estranho, tais quais os discursos individuais e coletivos, a maneira de dispor os objetos na mesa de trabalho, um olhar cabisbaixo ou um corpo mais altivo. Logo, o autor presente no campo se comprometeu a constantemente exercer o olhar de estranhamento, buscando investigar, por meio da observação do grupo, como o sistema de significados daqueles indivíduos é construído nos diferentes espaços.

\section{Análise dos Resultados}

Os dados emergentes do diário de campo resultaram na identificação de espaços-chaves com características próprias de comportamento dos indivíduos. São elas: a sala de reunião - com e sem a presença do presidente; o open office - com e sem o gerente -; e o espaço livre - composto pela copa e pelo almoço fora da empresa. A seguir, a análise por espaço.

\section{A sala de reunião}

Localizada no primeiro andar da sede da empresa, a sala de reunião possui tamanho razoável e comporta confortavelmente de seis a 12 lugares ao redor da mesa. É ainda um dos maiores ambientes da empresa, junto com a sala do Chief Executive Officer (CEO). Por ser o único ambiente destinado a reuniões, foi possível presenciar, essencialmente, dois tipos de encontro: o primeiro somente com a equipe do departamento de Desenvolvimento de Projetos e o segundo com a presença do CEO, a equipe de Projetos e, em alguns casos, terceiros.

\section{A sala de reunião com o presidente}

A dinâmica nesse ambiente revelou que, nos encontros com a participação do $\mathrm{CEO}$, este entra na sala somente após as pessoas principais da reunião já estarem presentes; a discussão começa, efetivamente, com a sua chegada. Notou-se que o Diretor da área de Projetos era um dos primeiros a chegar, seguido do Gerente e, por fim, dos analistas e estagiários. A ordem de entrada do grupo não foi, de maneira geral, sincronizada, mas sim hierarquizada. Observou-se que Gerente e Diretor, quando cientes da aproximação da reunião e/ ou de que o CEO já está a caminho, costumam descer rápido, sem muita delonga. Já os analistas, quando ouvem a ordem de descida, não param imediatamente as atividades; são um pouco mais vagarosos no processo de desprendimento da ação presente. Em alguns momentos, vão ao banheiro, para, entre outras coisas, "arrumar o cabelo e ver se está tudo OK", como disse a Analista 1 para a Analista 2, momentos antes de uma reunião (DIÁRIO, 2012). Em seguida, descem, chegando ligeiramente atrasados. Estagiários acompanham o ritmo dos analistas e descem com eles.

A descrição do ritual de descida, com efeito, delineia como o espaço, sob a ótica de Foucault (2002), contribui para um constante monitoramento de falas e atitudes dos indivíduos e permite explorar como analistas e estagiários demonstram sinais de contestação da cultura dominante. $\mathrm{O}$ atraso para dar início à reunião tende a marcar uma convenção de signos culturais que ocasiona uma subcultura do indivíduo diferente da que é estabelecida pela empresa, incorrendo na prática efetiva do atraso (FOUCAULT, 2007).

Não obstante, o discurso, nesse espaço, é muito formal, e não há falas sem permissão, ou seja, o indivíduo só se pronuncia quando questionado. Não é voluntária a participação, mas sim coercitiva. Nesse sentido, a interação que remete ao panoptismo de Foucault (2002) é exemplificada pelas atitudes do próprio CEO, que cobra constantemente soluções do Diretor e sua respectiva atenção: "Você está ouvindo, Diretor?"; "Você está vendo isso, Diretor?" (DIÁRIO, 2012). Apesar de a reunião ser realizada em equipe, o presidente faz questão de ressaltar que o responsável ali é o Diretor. Este, por sua vez, na medida em que é julgado, cobra de seus subordinados - que diretamente é o Gerente - entregas, testando-os, ao mesmo tempo em que é sabatinado. Essa situação de cobrança foi entendida como comum na sala de reunião, que refletia uma atmosfera tensa, sobretudo em função das possíveis reações do presidente. Em determinados momentos, há jogos de poder e sobreposições de comportamento, a exemplo de quando o Diretor é questionado pelo chefe sobre o status de um projeto (DIÁRIO, 2012):

Presidente: Diretor, me fale do projeto X! Diretor: Gerente, explica pra ele [o presidente] o status do projeto!

Gerente: Analistas, falem do projeto! 
Nesse caso, as analistas respondem, mas aparentam não gostar da inquisição; entreolham-se e respiram fundo, como se quisessem abafar um grito. Mas em nenhum momento há réplicas, até porque todos estão observando e sendo observados. Tal qual o prisioneiro no panóptico de Foucault (2002), a explícita exposição na sala de reunião gera um estado de alerta constante no vigiado, impactando no seu autocontrole e comportamento. Essa concepção é traduzida pela força do meio, que faz com que as analistas não rebatam a atitude do Gerente. Além disso, é latente descrever que naquele momento o CEO está no poder e seu questionamento é distribuído por toda a rede hierárquica da sala.

O espaço sala de reunião e as interações emergiram também na reflexão da apropriação de objetos e marcação de lugares. A observação do local mostrou que existe um acordo tácito que marca determinados assentos para cada pessoa. O presidente, no período analisado, sentou-se na mesma cadeira, do mesmo lado. O Diretor, na cabeceira da mesa, e o Gerente, ao seu lado esquerdo, fizeram o mesmo. Nas cadeiras restantes, analistas e estagiários revezam, mas sempre um par analista/estagiário fica junto, de cada lado da mesa.

Com efeito, a questão da apropriação dos objetos reflete a demarcação de território e a intenção, ainda que em âmbito psicológico, de delinear o espaço como expressão física de autoridade. Existe uma lógica, segundo Foucault (2002), que insere as pessoas em determinados lugares e possibilita o estabelecimento da presença do indivíduo na sua ausência, isto é, mesmo ausente, o sujeito se faz presente por meio da "sua cadeira", do "seu lugar". Nesse sentido, o espaço em análise sugere indivíduos que não apenas aceitam a marcação de assentos como atuam tais e quais vigilantes, realizando a manutenção da prática e excluindo/julgando quem a corrompe. Esse contexto é exemplificado pela fala dos próprios observados, como quando Estagiário 2 se dirige ao Estagiário 1: "Ei, você roubou o meu lugar! Eu sempre sento aí!" (DIÁRIO, 2012). Em outro momento, a vigilância toma forma e surge pela notificação entre os pares Analista 1 para Estagiário 3: "Ei, não sente aí. Aí é onde o CEO gosta de sentar. Esse é o lugar dele. Senta em outro canto que é melhor!" (DIÁRIO, 2012).

Com base nas premissas de Foucault (2002), pode-se afirmar que o controle do corpo e a dissonância do comportamento dos indivíduos no espaço estudado demonstram que a presença do CEO reforça uma relação de poder e formalidade no ambiente. Nessas ocasiões, tanto a apropriação do objeto quanto a análise do discurso revelam que a grandeza da hierarquia é ratificada, já que o efeito cascata ocorre múltiplas vezes: o CEO cobra do Diretor, que cobra do Gerente, que cobra dos analistas e estagiários. Além disso, os gestos e a expressão corporal de cada observado revelam que as relações mantidas na sala de reunião nem sempre ocorrem de forma conflituosa, mas sim consensual, impactando diretamente na maneira como o indivíduo se comporta dentro e, sobretudo, fora da sala.

\section{A sala de reunião com a equipe}

Já a dinâmica na sala de reunião com a equipe mostra que o movimento em direção ao local é retilíneo e funcionários se dirigem à sala em tempos aproximados, formando quase uma fila indiana. Não há esperas e todos descem muito sincronizados. A ordem de entrada no local também segue o mesmo fluxo de hierarquia da área. Foi identificada, ainda, a permanência dos lugares marcados, exceto pela ausência do CEO. A observação dos objetos, olhares e da postura neste cenário mostrou que a formalidade do espaço permanece forte, contudo, já há aqui diálogos e participações tímidas dos indivíduos. Nessa situação, analistas até fazem mais perguntas, discordam e, em alguns casos, anotam o que se passa. Contudo, agora, o Diretor é o centro e concentra a maior parte do foco da reunião, pois é ele quem cobra e dá respostas. Seu olhar não se mantém em uma pessoa só, mas é direcionado para todos.

Nesse contexto, foi observado que a Analista 1 demonstrou impaciência e indiferença. Em determinados momentos, desenhava na agenda, atitude que podia ser visualizada pelos estagiários e analistas, em razão do lugar que costumava ocupar. Já a Analista 2 tinha o hábito de mexer no celular, deixando o caderno de anotação aberto, em cima da mesa com a caneta. Esse comportamento chamou a atenção do Diretor, que, com expressão brava, disse certa vez: "Analista 2, preste atenção no que eu estou falando. Isso é importante e irei cobrar depois!". A resposta da Analista 2 foi educada, mas com tom bruto, como se estivesse controlando as emoções: "Ok [e deixa o celular na mesa]... Eu tô prestando atenção, Diretor.” (DIÁRIO, 2012).

$\mathrm{Na}$ perspectiva foucaultiana, as situações descritas podem ser entendidas como sinais de resistência ao que na sala é imposto. Quando a Analista 1 desenha durante a reunião, a ponto de os demais pares verem 
(exceto Gerente e Diretor), passa a mensagem de não coadunação com o que ocorre na sala. Com isso, ela faz uso do exercício do poder, na medida em que se expõe estrategicamente, não para todos. Nesse ponto, o poder propiciado pelo ambiente é tão intenso que não permite, contudo, que os pares se revoltem ou expressem liberalmente o que estão pensando. Em vez disso, atuam secretamente nos seus pensamentos e gestos. Aqui, cabe ressaltar a reflexão de Foucault (2002) sobre os corpos como espaços normalizadores.

A análise do ambiente permitiu compreender o molde do corpo, não propriamente da empresa, mas o do indivíduo. Quando a Analista 2 faz uso de sua personalidade para se mostrar diferente, valese da linguagem corporal para mostrar sua atitude. Isso é exemplificado pela constante manipulação do celular, voz firme e pelo olhar contestador. Para Foucault (2002), o poder, em toda a sua concepção, está ligado ao corpo, pois é sobre ele que se impõem as obrigações, as limitações e as punições. Assim, é factível a regulamentação do corpo humano como objeto e alvo de poder.

Não obstante, observou-se também o espaço como palco para firmamento de alianças, em que as figuras do Gerente e Diretor aparecem unidas. Em conversa com a equipe, o Gerente revela querer estar mais próximo dos seus subordinados, enquanto analistas e estagiários aparentam expressão indiferente, em alguns momentos até abaixam a cabeça. O Diretor reforça as palavras do Gerente, como se estivesse apoiando-o, ratificando o quão necessário é a equipe estar unida. Ainda fala que o comitê chamou-lhe a atenção, pois sua área está em constante conflito e dita sério que essa imagem precisa mudar "para a empresa toda ver" (DIÁRIO, 2012). A situação relatada mostra como a necessidade de aparentar estar bem diante de todo corpo organizacional é mais forte do que realmente estar bem com a equipe. A fala do Diretor "para a empresa toda ver" explicita que as dinâmicas de poder não estão apenas no espaço em si, mas por toda companhia. Cunhado em Foucault (2002), é possível compreender que o medo do julgamento e da sanção passível por toda organização incute no Diretor a obrigação de aparentar estar coeso com sua equipe, o que promove a dissonância entre o discurso ("quero estar bem") e a prática (estar efetivamente bem com a equipe).

A dinâmica no espaço sala de reunião com a equipe revelou traços de alienação nos observados, que parecem controlar suas emoções, mas, ao mesmo tempo, não fazem questão de escondê-las, sendo explícita a desatenção dada ao interlocutor. Quando comparado com os encontros do CEO, nota-se a permanência da formalidade, queé mais intensa quando o presidente está na sala. Não há uma padronização de atitudes nos dois casos examinados, embora o comportamento seja, na sua essência, parecido, pois reflete traços de desmotivação e/ou insatisfação de alguns pares em determinados momentos.

Logo, enquanto na sala de reunião com o presidente é notável um comportamento de velada submissão, obediência e ordem, com a sua ausência, é desmantelado a manutenção dessa postura. Com o presidente, ficou evidenciado uma preocupação, sobretudo corporal, em mostrar-se interessado no momento presente. Sem o presidente, ocorre um relaxamento do corpo, e por consequência, por mais que não haja conflitos diretos, é visível o desinteresse e/ou descontentamento com o dito na sala. Desse modo, a sala de reunião mostrou-se um local onde o encadeamento das ideias foucaultianas sobre espaço e poder se adéquam, na medida em que existe uma exposição explícita dos pares, que parece causar, entre outros fatores, constante automonitoramento dos indivíduos.

\section{O open office}

O Departamento de Projetos é marcado pela ausência de divisórias e lembra um grande retângulo. A visão da mesa do Diretor é global, ou seja, a posição que o indivíduo exerce naquele lugar permite a visualização e o controle de qualquer pessoa que estiver na sala. Os outros funcionários ficam em posições mais abertas e conseguem ver mais claramente o que o outro está fazendo e vice-versa. Existiram, no período observado, diferentes comportamentos, quando comparados com a relação com o Gerente, exigindo, portanto, aprofundamento de análise em ambas as situações.

\section{O open office com os pares}

As situações e a dinâmica entre pares no espaço organizacional open office variaram, sobretudo, em função da personalidade de cada um. Múltiplas notificações entre eles foram comuns, como por exemplo, quando o Estagiário 2 pergunta para a Analista 1 se esta conseguiu resolver o problema da sua geladeira: "[...] de tanto ouvir você falando no celular com a sua empregada sobre a geladeira, me envolvi, e agora quero saber como terminou isso; afinal, você conseguiu resolver?” (DIÁRIO, 2012). 
Analista 1 responde, um pouco sem graça. Nota-se que o uso da palavra "envolvi" é consequência da invasão que o espaço aberto proporciona. Remetendo-se aos estudos de Foucault (2002), não foi, portanto, uma obrigação física literal que fez com que a Analista 1 relatasse o desfecho de sua história, mas uma ação sutil e eficaz do espaço, que assumiu força tanto quanto um aprisionamento. Com a visibilidade excessiva, desmoronam-se as barreiras entre os aspectos pessoal e profissional, pois todo mundo ouve, vê e participa da vida alheia, o que, para Foucault (2002), marca a dissociação do par ver-ser visto.

No espaço observado, no entanto, nem todos afirmam prontamente a cultura da empresa, não aceitando de imediato o que lhes é exposto. Nesse aspecto, o olhar recriminador e a condenação da fala emergem como características principais de julgamento do par. Esse contexto é corroborado pela situação de euforia vivida entre os pares em prol do ganho de alguns brindes da empresa (DIÁRIO, 2012). Em determinado momento, foram distribuídos aos funcionários agendas, mousepads, canetas e bonecos, todos com o logotipo da companhia. Os itens foram rapidamente absorvidos, inserindo-se no cenário organizacional pela maioria. Entretanto, a Analista 2 revela não ter gostado de nada e se recusa a usar. Em tom sarcástico, pergunta se alguém quer os dela, pois, caso contrário, dará para terceiros; atitude que gera nos demais funcionários sentimentos de revolta, culminando em sua condenação: "Por que você não quer usar? Todo mundo da empresa vai usar a agenda! Coloca o mousepad também... aí todo mundo vai ficar igual, padrão...”, disse Analista 1. A resposta vem em tom sério e indiferente: "Uso nas reuniões a agenda que eu quiser. Eu prefiro um caderno que já usava e pronto.", rebate a Analista 2. Estagiário 2 também opina: "Analista 2, você é maluca!”. Analista 1 ainda insiste: Coloca então os bonequinhos no seu computador! Vai ficar legal, todo mundo igual!" (DIÁRIO, 2012).

De acordo com as ideias de Foucault (2002), o episódio de rebeldia aos olhos dos pares sobre a atitude da Analista 2 reflete o quanto a máquina do poder no espaço tende a estabelecer indivíduos como soldados fiéis da manutenção da cultura da empresa. A eficácia da lógica está justamente na repressão não mais por parte do supervisor de maneira direta, mas pela condenação entre os colegas de trabalho. É notável que em nenhum momento mencionou-se a obrigatoriedade de usar tais itens no espaço. Tudo aconteceu de forma muito sutil. O próprio Diretor não fez questão de usar. Mas a vigilância do espaço perante os demais quase que obriga a todos a se adequarem a uma nova regra: tem que usar, porque supostamente todo mundo vai usar. Não há, portanto, um questionamento da ação, mas uma efetiva obediência pela maior parte dos indivíduos. Por isso, quando alguém não aceita o ritual, é expurgado pelo grupo. A menção da palavra "maluca", na fala do Estagiário 2, reflete a perspectiva de Foucault (1979) sobre a loucura cabível nos ambientes organizacionais. Por mais metafórica que seja, a fala revela que quem não entra na regra do ambiente é considerado louco, como pelo fato de a Analista 2 enxergar no mousepad, por exemplo, um objeto sem valor, não necessariamente apoiando uma associação de afirmação da cultura da empresa.

Por isso, diante de um espaço submisso pela maioria, a Analista 2 se mostra personalista e usa do poder de que dispõe para se destacar e se fazer presente, o que é ainda evidenciado pela marcação feita na cadeira do escritório (DIÁRIO, 2012). Após reclamar que a sua cadeira vive sumindo ou sendo roubada, acaba com o problema, colando um papel com o seu nome atrás do objeto, para, assim, todos verem que a cadeira "tem dono". A Analista 1 e o Estagiário 3, de imediato, condenam a iniciativa, que consideram desnecessária. Ambos são ignorados pela Analista 2, que demarca a cadeira com expressão de satisfação. Em um local onde tudo é padronizado, o lugar da Analista 2 destaca-se, ora pela cadeira com nome, ora pelo mousepad e a agenda diferentes dos demais. Na perspectiva de Foucault (2002), trata-se de uma demonstração de poder no espaço, já que o intuito é exibir para os demais quão diferente a Analista 2 quer ser vista.

É crítico descrever que os conflitos e descontração entre os pares aconteciam de forma harmoniosa; apesar de haver posicionamentos diferentes, não houve calorosas discussões. Logo, é possível concluir que os indivíduos realizam ações agidos pelo poder e, nesse aspecto, a influência do outro toma forma em função da convivência proporcionada pelo espaço (FOUCAULT, 2002). Por isso, a interação entre os pares permeou múltiplos discursos, sensações, emoções e circunstâncias que colocaram os indivíduos em constante esfera de exibição. Por outro lado, a opção de alguns funcionários em colaborar com a manutenção da cultura da companhia revela a importância, para eles, de se manterem submisso às grades organizacionais que lhes são invisivelmente impostas, causando momentos de conflitos e condenações entre os pares. 


\section{0 open office com 0 gerente}

A dinâmica do espaço open office com o Gerente demonstrou situações de estresse e conflito. Essa questão é explicitada pela constante sensação de teste, propiciado pelo ambiente aberto e promulgado pelo Gerente, que costuma fazer inquisições abertas e na frente de todos, como: "Analista X, já fez o que eu mandei?"; "Você está demorando muito com o relatório, não sabe fazer?", "Por que você não me mandou a análise ainda?” (DIÁRIO, 2012). Com isso, foi identificado, por parte do Gerente, o uso excessivo do discurso imperativo e reiteração da hierarquia. Em determinada situação, ressaltou para o Analista 3 que este não deve sair da empresa antes de finalizar as entregas. Reforça na sua fala que ele é o Gerente e por isso deve ser obedecido. O Analista 3 não discute, mostra-se submisso, não fazendo nenhum comentário (DIÁRIO, 2012). O uso da expressão “eu sou seu Gerente" marca como o cargo é valorizado e tido como meio coercitivo para alcançar resultados. Dessa forma, o Gerente reforça sua autoridade, valendo-se apenas de sua posição e não de suas competências. A submissão do Analista 3 pode ser entendida como parâmetro para os demais, que, diante da exposição, são incutidos também de sentimentos que suscitam o controle de atitudes. Assim, o espaço convida sutilmente para o molde da fala (FOUCAULT, 2002).

Percebeu-se também que inúmeros conflitos envolveram a Analista 2, cuja personalidade, oposta à do Analista 3, fazia com que não aceitasse as condições impostas pelo espaço e, por isso, discutisse constantemente com o seu gestor. De modo análogo ao que ocorre no panóptico, a Analista 2 não vê a relação de poder com o Gerente de forma piramidal, exercendo, portanto, o poder por meio de situações de questionamento da capacidade de seu superior direto. À medida que o expõe, a Analista 2 incita no espaço uma visibilidade constante das atitudes do próprio Gerente, que é sabatinado por sua analista. A repetida fala de autoridade e o discurso são constantemente usados pela Analista 2 contra ele mesmo: "Se você é o Gerente, então deve saber!" (DIÁRIO, 2012). Quando questionado, o gestor fica exposto ao olhar recriminador do chefe e, ao mesmo tempo, proporciona o prazer dos pares ao redor. Para Foucault (2002), esse efeito bumerangue do poder é causado pela exposição explícita e fria do espaço aberto, causando assim relação de palco com quem está na sala.
Dessa forma, o ambiente estudado delineia um espaço organizacional instável, típico das organizações pósmodernas. Tal constatação é traduzida nas dinâmicas de poder entre os indivíduos e revelada na fala dos observados. Em muitos momentos, o Diretor afirma que "existem vários analistas no mercado; quem não está satisfeito, paciência" (DIÁRIO, 2012), referindose à própria cultura da empresa. A postura em relação ao Gerente também demonstra ser uma atitude de afirmação do poder hierárquico, corroborando a formalidade valorizada em excesso na organização: "Gerente, eu sei que você vai viajar, mas não se esqueça das entregas! Arranje um jeito de coordenar o pessoal, pois você é o Gerente! Resolva os problemas, pois irei te avaliar por isso!" (DIÁRIO, 2012).

Assim, o open office com os pares é marcado pela constante construção e desconstrução de alianças entre eles. É notável que a presença de pessoas com comportamento submisso e outras com comportamento mais questionador, impacta em diferentes situações onde um é influenciado pelo outro. Existe, dentro dessa dualidade, uma harmonia própria estabelecida pelos indivíduos. Não há um comportamento padronizado, mas sim uma padronização de transitoriedade de comportamento. Aqui, ora todos são influenciados pela Analista 2, ora nem todos ratificam o comportamento da Analista 2. Quando comparamos com a presença do Gerente, é nítida a formação de um individual coletivo. Neste cenário, o grupo, leia-se analistas e estagiários, se mostra um só. Por mais que haja comportamentos diferentes ao lidar com o gestor (enquanto o Analista 3 tende a ser mais submisso, a Analista 2 rebate), há um apoio implícito de todos na exposição do Gerente pela Analista 2. Quando esta usa do mesmo espaço para expor o Gerente, é visível entreolhares entre os pares e leves sorrisos entre si, denotando certo prazer coletivo em ver o Gerente sendo questionado (DIÁRIO,2012). Tal contexto marca uma esfera conflitante nesse ambiente.

\section{Espaço Livre}

A análise do caderno de campo permitiu evidenciar a existência de dois principais ambientes, que em termos físicos localizam-se fora do território de trabalho em si. Por essa característica, soam como livres, porém, conforme análise a seguir, possuem minúcias organizacionais tanto quanto os demais espaços. São eles: a copa e os almoços fora da empresa. 


\section{A copa}

Oficialmente classificada como espaço comum a todos, a copa assume caráter de vasta interação entre os membros da empresa. Tal ideia pode ser elucidada pela situação registrada nos momentos pósfesta de aniversário da companhia. No dia seguinte à comemoração, foram afixadas, nas paredes desse ambiente, fotos, por área, das pessoas que participaram. Desenvolvimento de Projetos foi o único setor cujos membros estavam ausentes. Para representar o departamento, estava apenas o Diretor. Com base no fato, foi comum ouvir, desde a copeira até diretores, comentários de condenação à equipe: "Nossa, vocês não foram! Que feio!”, "Poxa, ninguém da sua área foi prestigiar...", "Mas foi a festa da empresa, como vocês puderam faltar?" (DIÁRIO, 2012). A exceção do Diretor, presente na comemoração, todos os membros $\mathrm{da}$ equipe priorizam compromissos pessoais em detrimento do evento da organização. Porém, para os demais funcionários da empresa, independentemente das motivações pessoais dos indivíduos da equipe de projetos, ficou a imagem de desobediência. Por isso, com base em Foucault (2002), a copa admite ser um espaço propício para a manifestação de poder não por um, mas por qualquer funcionário: da alta hierarquia até a base, todos olham, classificam e julgam o outro.

As interações marcaram também um acordo peculiar entre os empregados, registrado pela mudança do discurso quando alguém entrava na copa. Foi comum ouvir reclamações das Analistas 1 e 2 e dos Estagiários 1 e 2 sobre o gestor. Porém, quando adentrava alguém de outro departamento, automaticamente a fala mudava: buscavam-se assuntos aleatórios, como futebol, viagens, e qualquer outro que não o anterior. Aqui, o controle do discurso pode ser interpretado como uma das consequências do impacto do espaço nas relações. O receio de outros funcionários ouvirem o que de fato cada um pensa acerca do chefe e/ ou da organização revela o ambiente como espaço manifestante do poder em sua forma mais essencial: na relação. Baseado em Foucault (2002), quando todos em sintonia mudam as falas, assinala-se um comportamento sistemático de defesa em função do ambiente.

De maneira geral, os almoços na copa da equipe de Projetos assumiram níveis de segregação, diminuindo até se dissiparem. A fala da Analista 1 para o Estagiário 1 reflete o pensamento dos pares sobre o momento do almoço no local: "Estagiário 1, vamos almoçar na rua.
Na copa não dá pra conversar direito!.”; “Almoçar fora é bom, pois ninguém fica ouvindo a gente e podemos conversar à vontade!", corrobora a Analista 2. Assim, em função da necessidade de liberdade do espaço e rompimento da vigilância sentida, o ambiente copa foi renegado pelo grupo e automaticamente substituído.

\section{0 almoço fora da empresa}

Nos almoços fora da companhia, observou-se que a separação diretor/gerente e analistas/estagiários passou a ser ainda mais comum, já que estes passaram a fazer questão de não almoçar com os chefes. Isso é revelado pelas respostas dos analistas quando perguntados pelos supervisores se queriam almoçar: "Vamos almoçar depois, estamos sem fome"; "Não, obrigada."; "Iremos comer em outro lugar". Nesses locais, foi comum o fato de se falar mal do chefe e/ ou dar a sua versão de determinado acontecimento, como se observou em conversa entre a Analista 1 e o Estagiário 1, sobre a reunião de feedback deste último (DIÁRIO, 2012). A Analista 1, que se mostrou firme e inflexível na sala de reunião, disse, no horário de almoço, que não concordava com algumas coisas que ela mesmo tinha dito, mas que teve que exaltar a parte negativa do feedback, pois o Gerente insistiu para que ela falasse algo.

Segundo Foucault (2002), a manifestação do poder no espaço em questão pode ser considerada latente, pois, apesar de estarem fora do ambiente profissional, os funcionários só falaram essencialmente do trabalho. Isso demonstra como a presença do Gerente, mesmo quando está ausente, é forte. Não há, aqui, apropriação de lugares, mas sim de falas, pois todo o discurso das Analistas 1 e 2 reflete um desafeto com o seu gestor. Trata-se da demonstração do impacto das relações que ocorrem dentro da empresa, expressa no comportamento dos indivíduos mesmo fora desta, traduzido em dissonâncias de discursos, exemplificada pela contradição assumida da Analista 1.

O momento de almoço fora da companhia possibilitou que as pessoas se sentissem mais livres para falar abertamente sobre algo que as incomoda na empresa, tal qual um desabafo. A manifestação do poder acontece suavemente, pois causa nos funcionários a sensação de liberdade de falar o que, possivelmente, gostariam de gritar na sala de reunião e/ou no open office. Tal licença, entretanto, é dúbia, visto que os colaboradores não conseguem se dissociar do próprio 
ambiente de trabalho, sequer no horário de almoço. Análogo à linha foucaultiana, as organizações, portanto, tendem a atuar de forma escravizadora, incutindo em seus funcionários dedicação infindável a ela. A lógica admite maior eficiência quando os próprios colaboradores, mesmo sem perceber, mantêm viva a empresa em seu discurso e comportamento, independentemente do espaço.

No espaço livre copa, é notável uma aparente descontração dos indivíduos, afinal, o local se mostra como acessível a todos da companhia. Porém, junto com esse convite de fácil acesso há o choque sutil do encontro com outros funcionários. Com frequência, foi possível perceber pequenos cochichos entre pessoas e mudanças repentinas de conversa quando adentra alguém na copa. Essa característica de tensão provocou nos observados um contínuo controle da fala, já que, mesmo ali, tudo era vigiado, e não apenas por uma pessoa, mas por todos inseridos no ambiente. Diante da sensação de sufocamento organizacional, foi instigada pelos próprios pares a busca de liberdade da empresa, sendo priorizados os almoços fora da companhia. Em sua maioria sem o Gerente e Diretor, os pares enxergavam nesses momentos, uma tentativa de se desvencilhar do universo organizacional. Porém, o que aconteceu é que esses momentos serviram de palco para a exposição aberta de reais opiniões de situações vividas na empresa. Ao contrário do controle da fala na copa, aqui, há o total descontrole do discurso, sendo comum nesse espaço, uma total reflexão do trabalho, tal qual uma catarse.

\section{Discussão}

Os espaços focados neste estudo permitiram compreender como, no ambiente de trabalho, são manifestadas as dinâmicas de poder e quais impactos demarcam nos indivíduos da empresa. A hierarquia, característica envolta às situações, foi entendida como item valorizado na empresa. Contudo, nos espaços observados, nota-se a manifestação do poder para além da subordinação empresarial: está incutida nas relações entre os próprios funcionários e é vibrante principalmente nas formas de atuação da cultura da empresa. Influenciados pelo pensamento da companhia, percebe-se, por parte dos observados, a criação e manutenção sutil de regras que não necessariamente existem no papel, mas possuem força tanto quanto as diretrizes da organização.
O papel da Analista 2 assume fundamental importância para a compreensão do poder nos espaços em questão, já que sua personalidade questionadora dos padrões preestabelecidos reflete quão ela quer se fazer destacável dos outros, o que, de fato, consegue. A irradiação de sua personalidade traz à tona a mudança de comportamento dos outros pares, comprovada pelo desabafo da Analista 1: " [...] depois que você entrou na empresa, Analista 2, fiquei muito mais grossa com o Gerente" (DIÁRIO, 2012). O comentário é exemplo de como o espaço aberto influencia a convivência do grupo e cria, inclusive, conflitos internos ao próprio indivíduo. É importante ressaltar que a atitude personalista da Analista 2 não a torna isenta dos efeitos do panóptico e muito menos a define como uma pessoa boa ou ruim, ainda que assuma um comportamento contrário ao que o ambiente solicita. Para Foucault (2002), não existe caráter maligno nas relações de poder, mas sim fontes de produção de conhecimento e saber, não havendo, portanto, cabimento do julgo de valor do indivíduo (ALCADIPANI; ALMEIDA, 2000). Todavia, a presença da Analista 2 revela uma relação questionadora da ordem, pois ela enfrenta o gerente mesmo ele estando acima dela na hierarquia, ou seja, não é aceitado por todos, no ambiente organizacional, a grandeza do organograma.

Entende-se o espaço, no estudo de caso aplicado, como propulsor da manifestação do poder em sua forma menos clássica: a cobrança e obediência do espaço organizacional não vêm necessariamente da diretoria, mas de todos que compõem o cenário de convivência e ratificam sutilmente, no cotidiano de trabalho, a própria cultura da empresa. Assim, compreendem, na organização do objeto do estudo, para além dos espaços em si, relações latentes do indivíduo que o permeiam e, principalmente, influenciam diretamente na sua forma de agir e até mesmo produzir. Nesse sentido, a pesquisa etnográfica proporcionou aos autores mapear a dinâmica de poder nos espaços obervados, assim como o respectivo comportamento dos indivíduos, destacados na Figura 3. 
Figura 3. Classificação dos espaços organizacionais

\begin{tabular}{|c|c|c|c|c|}
\cline { 2 - 5 } \multicolumn{1}{c|}{} & Sala de Reunião & Open Office & Copa & $\begin{array}{c}\text { Almoço fora da } \\
\text { empresa }\end{array}$ \\
\hline Caracterização do Ambiente & Espaço Coercitivo & Espaço Conflitante & Espaço Passivo & Espaço Catártico \\
\hline Dinâmica de Poder Identificada & Submissão & Confronto & Dissimulação & Reflexão \\
\hline Comportamento Observado & $\begin{array}{c}\text { Obediência aos } \\
\text { superiores }\end{array}$ & $\begin{array}{c}\text { Discussão entre pares e } \\
\text { superiores }\end{array}$ & $\begin{array}{c}\text { Discurso dissonante entre } \\
\text { os pares e o restante da } \\
\text { empresa }\end{array}$ & Descontrole da fala \\
\hline
\end{tabular}

Fonte: Desenvolvido pelos autores

Cada espaço solicitou determinada expectativa, que é formulada e atendida pelos próprios funcionários; portanto, marca um modelo de comportamento organizacional. $\mathrm{Na}$ sala de reunião, há uma assumida e consentida submissão dos funcionários pelo que é solicitado. Independentemente da presença do CEO, o ambiente se revela coercivo e cerceador dos indivíduos, caracterizado, sobretudo, pela obediência velada destes aos superiores. A externalização de uma possível insatisfação ao que acontece na sala ocorre essencialmente em âmbito psicológico e é revelado nos traços corporais de cada funcionário: por meio do molde do corpo, todos obedecem sem questionar a ordem.

No open office, é desmitificada essa regra de submissão da sala de reunião; o embate é compartilhado com o superior direto e entre pares. Há fortes discussões com os chefes e divergências de posicionamento entre os colegas de trabalho. Lá, o espaço organizacional ratifica a manifestação de poder na sua bilateralidade, descrita por Foucault (2002): o mesmo ambiente que mostra quem é o superior serve para testá-lo de sua superioridade pelo grupo. A exibição adquire dimensão para além do poder hierárquico, pois todos nesse espaço participam, ainda que de forma expectadora, do que acontece no local, tornando-o um ambiente essencialmente conflitante.

Já na copa, o efeito panóptico tem como característica a universalidade do monitoramento. Todos estão sujeitos a olhares alheios. Essa transitoriedade marca o local como palco para dissimulações de discursos entre os funcionários, que, reféns do espaço nu e sob jugo do outro, desenvolvem mecanismos de proteção revelados pela troca da fala sistemática e em sintonia diante dos demais da organização. Assim, a copa marca um espaço organizacional de passividade, onde o sujeito se adéqua às regras tácitas do local.

Todo esse contexto corporativo culmina na dinâmica observada nos almoços fora da empresa. A busca pelo "desabafo" mostra como as empresas conseguem, frequentemente, incutir nos funcionários necessidades que implicam a extensão do trabalho. Nesse cenário, para além do espaço físico, percebem-se os tentáculos da organização por meio de uma invasão sutil na vida dos colaboradores. Por mais que estejam fora da empresa, o assunto é com pertinência a própria companhia. Nesse ponto, torna-se difícil definir os limites entre a vida pessoal e a profissional do indivíduo, trazendo à luz mecanismos de poder que se mantêm pelo envolvimento psicológico do funcionário e materializado pelas extensões do discurso revelado nos momentos fora da empresa. Cabíveis no contexto, os celulares corporativos e a ideia do home office se encaixam na proposição, pois ambos tendem a se estender e se infiltrar na vida pessoal do funcionário, causando, segundo Foucault (2002), a constituição de espaços organizacionais para além do escritório em si. Logo, a necessidade de fugir do local físico de trabalho para desabafar gerou momentos de reflexão nos funcionários, ocasionando, assim, verdadeiros espaços catárticos, marcados pela dissonância e pelo descontrole do discurso. 


\section{Conclusão e Sugestões para Pesquisas Futuras}

O estudo visou compreender como os espaços organizacionais contemporâneos impactam na dinâmica e no comportamento entre os indivíduos, revelando mais profundamente uma leitura do poder nas organizações, baseado, sobretudo, em Foucault (2002). Conclui-se que, dentre outros fatores, o espaço nu provoca uma espécie de efeito espelho no funcionário: o envolvimento com a empresa e as situações de vivência em um ambiente aberto e em grupo fazem com que o indivíduo olhe com frequência para si e se questione de valores internos. Isso é explicado pelos momentos de dissonâncias nos autodiscursos e nas condenações mútuas das atitudes por parte dos próprios funcionários. Assim, é latente a importância de descrever a influência da cultura da empresa no comportamento do colaborador.

A participação do corpo organizacional na manutenção e criação de regras tácitas demonstra a identidade da organização nas entranhas da identidade do indivíduo. Permeado pela cultura da companhia, esse envolvimento sutil contribui para que os interesses organizacionais sejam, na verdade, alimentados como se fossem os do próprio funcionário. Palco dessas tramas corporativas e participante da dinâmica entre indivíduos, os mecanismos de poder são distribuídos por toda a organização, indo para além do espaço físico. Por isso, tais ambientes se instalam criticamente como estruturas de monitoramento e controle, que envolvem os participantes numa rede psicológica e culminam diretamente em comportamentos instantâneos de defesa em prol do espaço inserido.

Nesse sentido, os aspectos observados propõem a existência de quatro espaços-chaves, emergentes na manifestação do poder em uma organização: coercitivo, conflituoso, passivo e catártico. Esses ambientes mostraram-se distintos, quando comparados, trazendo à luz comportamentos influenciados, sobretudo, pelo meio. Foi possível notar dinâmicas singulares, o que, de modo geral, dá margem para compreender determinados espaços organizacionais como agentes que promovem e incitam específicos tipos de relação de poder caracterizados justamente pelo ambiente.

Os resultados encontrados suscitam uma discussão mais ampla sobre o gerenciamento do corpo organizacional, lançando ótica sob a origem de tudo: o próprio indivíduo. Diante de múltiplas variáveis da dinâmica do poder que influenciam o comportamento do funcionário, fica o desafio da empresa em lidar com esses conflitos, muitas vezes tidos como subjetivos. O presente artigo transparece que as situações aparentemente cotidianas do ambiente de trabalho impactam diretamente na forma como o indivíduo lida com as questões organizacionais, compreendendo desde a sua postura até a identificação com a cultura da companhia. Como ponto crítico de análise, destacamos a aplicação dos achados na administração em geral: Como estimular um ambiente pleno e realizado, diante de anseios e dissonâncias humanas? Como lidar com a transitoriedade do comportamento humano em um cenário empresarial cada vez mais competitivo? Logo, derrubam-se as grades do open office e propõem-se uma maior interação entre os indivíduos. Porém, o identificado é que as grades não desaparecem, mas se tornam intrínsecas ao espaço, transformando a interação entre indivíduos $\mathrm{em}$ fenômenos onde as relações de dominação e poder permanecem a existir, contudo, transvestido pela nudez do espaço organizacional.

Por fim, cumpre ressaltar que a deflagração de como ocorrem os mecanismos de poder sutis em um espaço corporativo não tem como objetivo desmoralizar os indivíduos. Como parte do processo crítico organizacional, as ponderações acerca do espaço e poder deste artigo ilustram dinâmicas típicas de um ambiente profissional, agregando aos gestores outras variáveis que envolvem uma possível tomada de decisão. As interações existentes nos espaços organizacionais e suas dinâmicas de poder são apenas mais um detalhe no universo de análises que tangenciam, na contemporaneidade, o modelo de gestão de pessoas e, sobretudo, a administração de empresas. Nessa perspectiva, pode-se destacar, por exemplo, o quanto os espaços abertos tendem a fomentar funcionários teatrais, que atuam perante todos da organização. A exposição pode dar origem a "colaboradores personagens", que agem dessa forma com diversas finalidades: para agradar ao chefe, para se enturmar ou para ostentar uma imagem. Mesmo não sendo foco do diário, temas como esses foram identificados como caminhos de exploração em futuros estudos e pesquisas. 


\section{Referências Bibliográficas}

ADORNO, R. C. F.; CASTRO, A. L. O exercício da sensibilidade: pesquisa qualitativa e a saúde como qualidade. Saúde e Sociedade, São Paulo, v. 3, n. 2, p. 172-85, 1994.

ALCADIPANI, R.; ALMEIDA, A. O. A. O feitiço incluiu o feiticeiro: uma análise sobre a implementação de um escritório aberto.

ENCONTRO NACIONAL DA ANPAD, 24. 2000, Florianópolis. Anais... Florianópolis: ANPAD, 2000.

DIÁRIO. Anotações pessoais. Rio de Janeiro, abril/ jul. 2012.

FILHO; N. G. S. O poder nas organizações: vertentes de análise. Científico, Salvador, ano II, v. I, ago./dez., 2002.

FOUCAULT, M. Foucault por ele mesmo. França, cop. 2003. 1 videocassete (63 min), VHS.

. Vigiar e punir: nascimento da prisão.

Petrópolis: Vozes, 2002.

. Microfísica do poder. Petrópolis: Vozes,

1979.

Em defesa da sociedade. SP: Martins

Fontes, 2005.

As palavras e as coisas. SP: Martins

Fontes, 2007.

GIL, A. C. Como elaborar projetos de pesquisa.

4. ed. São Paulo: Atlas, 2008.

MACHADO, R. Por uma Arqueologia do Poder.

In: _. Microfísica do poder. Rio de Janeiro:

Graal, 1979.

MAGNANI, J. G. C. De perto e de dentro: nota para uma etnografia urbana. Revista Brasileira de Ciências Sociais, v. 17, n. 49, 2002.

SEGNINI, L. Bradesco: a liturgia do poder. 1986. Tese (Doutorado) - Pontifícia Universidade Católica, São Paulo, 1986.

VERGARA, S. C. Métodos de pesquisa em administração. 2. ed. São Paulo: Atlas, 2006.

; GOMES, A. P. C. Z. Escritórios abertos: interação ou controle? Revista de Administração Pública - RAP, Rio de Janeiro: Fundação Getúlio Vargas, v. 37, n. 4, jul./ago., 2003. 